\title{
Statistical analysis and optimization of the corrosion inhibition efficiency of a locally made corrosion inhibitor under different operating variables using RSM
}

\author{
J.A.A. Yamin, ${ }^{1 *}$ E. Ali Eh Sheet ${ }^{2}$ and A. Al-Amiery ${ }^{3}$ \\ ${ }^{I}$ The University of Jordan, School of Engineering, Mechanical Engineering Department, \\ Amman 11942, Jordan \\ ${ }^{2}$ Energy and Renewable Energies Technology Center, University of Technology-Iraq, \\ Baghdad 10066, Alsenaa Street, Iraq \\ ${ }^{3}$ Applied Science Department, University of Technology-Iraq, Baghdad 10066, Alsenaa \\ Street, Iraq \\ *E-mail:yamin@ju.edu.jo
}

\begin{abstract}
Corrosive solutions such as hydrochloric acid find huge applications in many manufacturing processes such as pickling, cleaning and acid removal techniques due to effective cleaning procedures and low costs. The utilization of corrosion inhibitors is a significant practical technique to reduce the corrosion of mild steel in corrosive solutions. Organic molecules with hetero atoms such as sulfur, phosphorous, oxygen, and nitrogen are the best corrosion inhibitors. 4-Amino-3-(2-bromo-5-methoxyphenyl)-1H-1,2,4-triazole-5(4H)-thione (ATH) was synthesized by cyclization of 2-bromo-5-methoxybenzohydrazide in the presence of carbon disulfide and hydrazine. ATH was characterized by proton, carbon-13 nuclear magnetic resonance (NMR) and Fourier transform infrared (FT-IR) spectroscopy techniques in addition to carbon, hydrogen and nitrogen elemental analysis (CHN elemental analysis). ATH was investigated as a sustainable inhibitor for mild steel corrosion in acidic medium using corrosion experiments. Response surface method (RSM) was used in obtaining the optimum operating conditions, interactive and main effect of the parameters inhibiting the mild steel corrosion. The coefficient of determination $\left(R^{2}\right)$ and ANOVA (analysis of variance) proved the RSM method appropriate for the optimization of waste product inhibition on mild steel. The predicted and experimental values from the model are in good agreement. This study suggests that (ATH) is a promising significant corrosion inhibitor.
\end{abstract}

Keywords: mild steel corrosion, response surface method, optimization, 4-amino-3-(2bromo-5-methoxyphenyl)-1H-1,2,4-triazole-5(4H)-thione.

Received: January 12, 2020. Published: April 14, 2020

doi: $\underline{10.17675 / 2305-6894-2020-9-2-6}$ 


\section{Introduction}

Corrosion is an important and critical issue faced in various industries. The offshore structures exposed to chloride solutions, rain, condensation, and water, constantly lead to severe deterioration. The pitting and localized corrosion are caused by chloride ion which depassivate the metal and makes them susceptible to deterioration at certain threshold chloride concentrations [1-3].

Among various methods of preventing mild steel corrosion in chloride solution, the use of inhibitor has been considered the best method owing to its practical technique and low cost. Inhibitor efficiency depends on the nature of the metal surface, environment and inhibitor structure $[4,5]$.

Organic compounds having hetero-atoms such as $\mathrm{S}, \mathrm{N}$ and $\mathrm{O}$ have been reported by different researchers as efficient inhibitor for various metals [6-10].

The common inhibitors that were being used are nitrates, benzoates, phosphates, and chromates. In recent times, the eco-friendly corrosion inhibitor is been used to control metallic corrosion to replace the toxic, expensive and scarce corrosion inhibitors. Experiments are useful in explaining the corrosion inhibition mechanism, however, they are time-consuming because it is constantly based on large-scale trial and error experiments and also expensive.

RSM is used widely in different engineering fields to optimize the engineering process, estimate the individual factor effect and their interactive effect. Therefore, RSM could be applied in inhibition of mild steel corrosion due to its ability to reduce process duration, process variables, and overall cost. Hence, the aim of this study was to identify the optimal conditions for $(\mathrm{ATH})$ inhibition and examine the effects of concentration, temperature and exposure time on (ATH) inhibition using the RSM approach. Microscopic examination of the mild steel surface after weight loss tests was also discussed in this study.

\section{Experimental work}

\section{Chemistry and synthesis of the corrosion inhibitor}

Solvents and starting materials were purchased from Sigma Aldrich Malaysia and have been utilized as they are. The melting point was measured (uncorrected) utilizing the standard melting point device. FT-IR spectrum was performed on 8300 spectrometer/Shimadzu. $\mathrm{CHN}$ analyses have been done through using of $5500 \mathrm{CHN}$ elemental analyzer/Carlo Erba. The NMR spectrum was recorded in at $300 \mathrm{MHz} /$ Bruker Spectrospin with internal standard namely tetramethylsilane.

Bromo-5-methoxybenzohydrazide was synthesized by refluxed an ethanolic solution of equimolar quantities of methyl 2-bromo-5-methoxybenzoate $(0.03 \mathrm{~mol})$ and hydrazine hydrate $(0.03 \mathrm{~mol})$ for $5 \mathrm{~h}$.

The thin-layer chromatography technique was used to monitor the completion of the reaction. The reaction mixture was cooled, then filtered, dried and recrystallized from ethanol. Yield $83 \%$, FT-IR $\left(v \max \mathrm{cm}^{-1}\right): 3348.5$ and 3219.1 for amino groups; 3077.5 
(Aromatic $\mathrm{C}-\mathrm{H}) ; 2877.8\left(-\mathrm{OCH}_{3}\right), 1651.3\left(\mathrm{C}=\mathrm{O}\right.$ stretching), $766.2(\mathrm{C}-\mathrm{Br}) .{ }^{1} \mathrm{H}$ NMR in DMSO-d 6 : $\delta(\mathrm{ppm}) 3.78\left(2 \mathrm{H}, \mathrm{s}, \mathrm{NH}_{2}\right), 3.53\left(3 \mathrm{H}, \mathrm{s},-\mathrm{CH}_{3}\right), 7.21-7.40(\mathrm{H}, \mathrm{m}, \mathrm{Ar}-\mathrm{H}), 8.93$ $(1 \mathrm{H}, \mathrm{s}, \mathrm{NH}) .{ }^{13} \mathrm{C}$ NMR in DMSO-d 6 : $\delta$ (ppm) 114.1, 119.2, 122.9, 134.4, 139.5 and 143.6 for (carbon benzene ring), 55.2 (methyl) and 161.7 for carbonyl group. CHN Analysis. Calculated/found for $\mathrm{C}_{8} \mathrm{H}_{9} \mathrm{BrN}_{2} \mathrm{O}_{2}$ : C, 39.21/38.99, H, 3.70/3.57, N, 11.43/11.81.

4-Amino-3-(2-bromo-5-methoxyphenyl)-1H-1,2,4-triazole-5(4H)-thione accordingly: carbon disulfide $(0.039 \mathrm{~mol})$ was added to a mixture of 2-bromo-5-methoxybenzohydrazide $(0.03 \mathrm{~mol})$ with absolute ethanol $(50 \mathrm{ml})$ and potassium hydroxide $(4.6 \mathrm{~g})$. The mixture was stirred for 10 hours at room temperature. Then diethyl ether $(30 \mathrm{~mL})$ was added to the mixture with shaking for one hour. The salt was separated, filtered and washed with ether $(15 \mathrm{~mL})$. Hydrazine hydrate $(0.06 \mathrm{~mol})$ was added gradually to a mixture of potassium salt $(0.03 \mathrm{~mol})$ and water $(36 \mathrm{ml})$ then refluxed for 3 hours. The $\mathrm{H}_{2} \mathrm{~S}$ gas evolved and the color changed to dark green. The resulting mixture was cooled to $5^{\circ} \mathrm{C}$ and then acidified by hydrochloric acid to $\mathrm{pH} 1.00$. The mixture was filtered and the product was washed with distilled water and recrystallized from ethanol. IR $(\mathrm{KBr}) \gamma / \mathrm{cm}^{-1}: 3171.36-3300.57\left(\mathrm{NH}_{2}\right.$ stretching), 3071.36 (aromatic $\mathrm{CH}$ stretching), 2939.95 (methyl $\mathrm{CH}$ stretching), 1611.23 $\left(\mathrm{C}=\mathrm{N}\right.$ stretching), $1493.11(\mathrm{C}=\mathrm{S}), 746.93(\mathrm{C}-\mathrm{Br}) ;{ }^{1} \mathrm{H}$ NMR: $\left(\mathrm{DMSO}-\mathrm{d}_{6}\right): \delta 3.78(\mathrm{~s}, 3 \mathrm{H},-$ $\left.\mathrm{OCH}_{3}\right), 6.17\left(\mathrm{dd}, 1 \mathrm{H}, J=8.6,2.8 \mathrm{~Hz}\right.$ for $\left.-\mathrm{NH}_{2}\right), 7.34-7.38(\mathrm{dd}, 2 \mathrm{H}, J=2.8,0.5 \mathrm{~Hz}, \mathrm{ArH})$, 7.58-7.79 (dd, $1 \mathrm{H}, J=8.4 \mathrm{~Hz}, \mathrm{ArH}) ;{ }^{13} \mathrm{C}$ NMR (DMSO-d 6 ): $\delta 55.97,112.31,116.11$, 120.91, 127.04, 133.51, 147.22, 157.11, 170.31; CHN Analysis. Calculated/found for $\mathrm{C}_{9} \mathrm{H}_{9} \mathrm{BrN}_{4} \mathrm{OS}$ : C, 35.89/36.22; H, 3.01/3.08; N, 18.60/18.67.
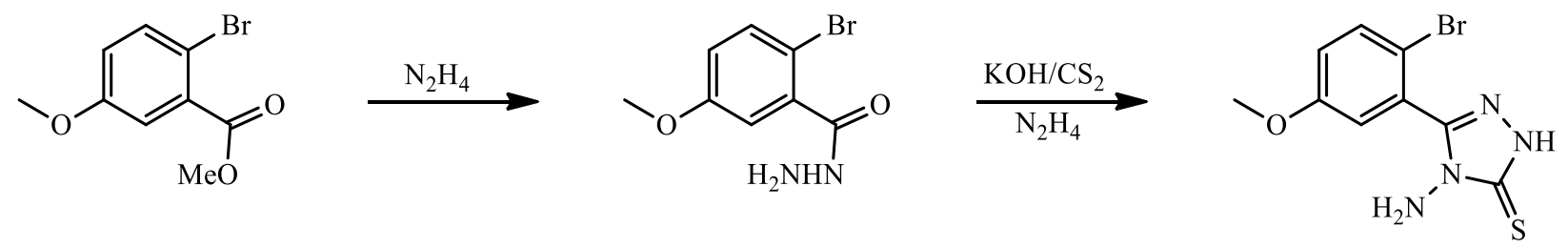

Figure 1. The synthesis of the corrosion inhibitor.

\section{Corrosion test}

Coupons of mild steel with dimension s of $2.5 \mathrm{~cm} \times 2.0 \mathrm{~cm} \times 0.05 \mathrm{~cm}$ with the composition (wt. \%): $99.21 \% \mathrm{Fe} ; 0.21 \% \mathrm{C} ; 0.38 \% \mathrm{Si} ; 0.09 \% \mathrm{P} ; 0.05 \% \mathrm{~S} ; 0.05 \% \mathrm{Mn}$ and $0.01 \% \mathrm{Al}$ were used for weight loss and surface analysis studies.

The mild steel coupons were mechanically polished utilizing various grades of emery papers, then the use of acetone for degreased and then washed with distilled water, dried and stored for use. A solution of $\mathrm{HCl}$ (hydrochloric acid $37 \%$ analytical grade) was diluted with distilled water for the purpose of preparing a $1 \mathrm{M}$ acid solution with and tests were performed at $303 \mathrm{~K}$. 


\section{Gravimetric study}

Weight loss tests were performed by immersion in the mild steel coupons in $100 \mathrm{~mL}$ of the $\mathrm{HCl}$ environment of 1 molar, in the presence of corrosion inhibitor in concentrations of 0.0 , $0.01,0.02,0.03,0.04$ and 0.05 at $303 \mathrm{~K}$.

After immersion of mild steel coupons for 5 hours, the coupons were washed with distilled water, acetone, dried, and re-weighed to calculate weight loss, using the ASTM procedure $[11,12]$. These experiments were repeated two times, using average weight loss values to calculate the corrosion rate $\left(C_{\mathrm{R}}\right),\left(\mathrm{mg} \cdot \mathrm{cm}^{-2} \cdot \mathrm{h}^{-1}\right)$ according to equation $1[10,13]$.

$$
C_{\mathrm{R}}=\frac{w}{A t}
$$

Where $w$ is the weight loss (mg), $A$ is the area of mild steel coupon $\left(\mathrm{cm}^{-2}\right)$, and $t$ is the immersion time $\left(\mathrm{h}^{-1}\right)$. The inhibition efficiencies and surface coverages can be calculated according to equations 2 and 3 respectively [14].

$$
\begin{gathered}
I E(\%)=\frac{C_{\mathrm{R}}-C_{\mathrm{Ri}}}{C_{\mathrm{R}}} \\
\theta=\frac{C_{\mathrm{R}}-C_{\mathrm{Ri}}}{C_{\mathrm{R}}}
\end{gathered}
$$

Where $C_{\mathrm{R}}$ is the corrosion rate in the absence of the tested inhibitor, and $C_{\mathrm{Ri}}$ is the corrosion rate in the presence of the tested inhibitor.

\section{Surface morphology analysis}

Morphology of the MS surface that was immersed in a corrosive solution with/without the inhibitor was done in this method. The concentration used in this test was $1000 \mathrm{~g} / \mathrm{L}$ at room temperature of $303 \mathrm{~K}$ for 5 hours. Surface analysis was done using the SEM technique.

\section{Design of experiments using response surface method}

The response surface method is a set of statistical and mathematical techniques to model and analyzes problems where the response of interest is influenced by different variables [15]. This method was adopted due to its ability to estimate interactive effect between tested parameters, and its limiting ability of actual experimental number to be carried out compared to other methods.

The key parameters influencing inhibitor performance were believed to be exposure time, inhibitor concentration and temperature [16].

Response Surface Methodology (RSM) model at different levels for three variables was used as the experimental design model. More than 100 readings were used in calculating the polynomial equation coefficients fitted to the experimental data.

In this study, (ATH) concentration, temperature and exposure time were the independent variables. After the determination of parameters, a mathematical model was 
used to plot a three-dimensional graphics for all reaction factors and optimal reaction conditions were determined to obtain the optimum operating condition for the inhibitor.

In addition, analysis of variance was utilized to establish the relationship between experimental and predicted values using statistical parameters [15]. The model terms are tested by Fisher's exact test ( $F$ value) and significance probability $(P$-value).

Shown in Table 1 is the experimental range, independent variables, and design model levels. The actual matrix experimental design is shown in Table 2.

In developing corrosion process regression equations, the third-order polynomial equation was used. The main interactive effect of the possible factor combinations has been estimated. The proposed equation for which the coefficients were sought to be found was:

$$
Y=\beta_{0}+\beta_{1} \cdot x_{1}+\beta_{2} \cdot x_{2}+\beta_{3} \cdot x_{3}+\beta_{4} \cdot x_{1}^{2}+\beta_{5} \cdot x_{2}^{2}+\beta_{6} \cdot x_{3}^{2}+\beta_{7} \cdot x_{1} x_{2}+\beta_{7} \cdot x_{1} x_{2}+\beta_{8} \cdot x_{1} x_{3}+\beta_{9} \cdot x_{2} x_{3}
$$

Where $x_{1}, x_{2}$, and $x_{3}$ are the concentration, time and temperature respectively.

Table 1. Experimental range and variable levels.

\begin{tabular}{ccc}
\hline Variable & Low-Level Factor & High-Level Factor \\
\hline Inhibitor Concentration $(\mathrm{mg})$ & $-1(0 \mathrm{mg})$ & $+1(5 \mathrm{mg})$ \\
\hline Temperature $\left({ }^{\circ} \mathrm{C}\right)$ & $-1\left(30^{\circ} \mathrm{C}\right)$ & $+1\left(60^{\circ} \mathrm{C}\right)$ \\
\hline Exposure Time $(\mathrm{hr})$ & $-1(1 \mathrm{hr})$ & $+1(48 \mathrm{hr})$ \\
\hline
\end{tabular}

Table 2. Experimental design for RSM model design in terms of actual variables.

\begin{tabular}{ccccccc}
\hline StdOrder & RunOrder & Blocks & PtType & Concentration & Time & Temperature \\
\hline 1 & 1 & 1 & 1 & 0.0 & 1 & 303 \\
2 & 2 & 1 & 1 & 0.1 & 1 & 303 \\
3 & 3 & 1 & 1 & 0.2 & 1 & 303 \\
4 & 4 & 1 & 1 & 0.3 & 1 & 303 \\
5 & 5 & 1 & 1 & 0.4 & 1 & 303 \\
6 & 6 & 1 & 1 & 0.5 & 1 & 303 \\
7 & 7 & 1 & 1 & 0.0 & 1 & 313 \\
8 & 8 & 1 & 1 & 0.1 & 1 & 313 \\
9 & 9 & 1 & 1 & 0.2 & 1 & 313 \\
10 & 10 & 1 & 1 & 0.3 & 1 & 313 \\
11 & 11 & 1 & 1 & 0.4 & 1 & 313 \\
12 & 12 & 1 & 1 & 0.5 & 1 & 313 \\
13 & 13 & 1 & 1 & 0.0 & 1 & 323 \\
\hline
\end{tabular}




\begin{tabular}{|c|c|c|c|c|c|c|}
\hline StdOrder & RunOrder & Blocks & PtType & Concentration & Time & Temperature \\
\hline 14 & 14 & 1 & 1 & 0.1 & 1 & 323 \\
\hline 15 & 15 & 1 & 1 & 0.2 & 1 & 323 \\
\hline 16 & 16 & 1 & 1 & 0.3 & 1 & 323 \\
\hline 17 & 17 & 1 & 1 & 0.4 & 1 & 323 \\
\hline 18 & 18 & 1 & 1 & 0.5 & 1 & 323 \\
\hline 19 & 19 & 1 & 1 & 0.0 & 1 & 333 \\
\hline 20 & 20 & 1 & 1 & 0.1 & 1 & 333 \\
\hline 21 & 21 & 1 & 1 & 0.2 & 1 & 333 \\
\hline 22 & 22 & 1 & 1 & 0.3 & 1 & 333 \\
\hline 23 & 23 & 1 & 1 & 0.4 & 1 & 333 \\
\hline 24 & 24 & 1 & 1 & 0.5 & 1 & 333 \\
\hline 25 & 25 & 1 & 1 & 0.0 & 5 & 303 \\
\hline 26 & 26 & 1 & 1 & 0.1 & 5 & 303 \\
\hline 27 & 27 & 1 & 1 & 0.2 & 5 & 303 \\
\hline 28 & 28 & 1 & 1 & 0.3 & 5 & 303 \\
\hline 29 & 29 & 1 & 1 & 0.4 & 5 & 303 \\
\hline 30 & 30 & 1 & 1 & 0.5 & 5 & 303 \\
\hline 31 & 31 & 1 & 1 & 0.0 & 5 & 313 \\
\hline 32 & 32 & 1 & 1 & 0.1 & 5 & 313 \\
\hline 33 & 33 & 1 & 1 & 0.2 & 5 & 313 \\
\hline 34 & 34 & 1 & 1 & 0.3 & 5 & 313 \\
\hline 35 & 35 & 1 & 1 & 0.4 & 5 & 313 \\
\hline 36 & 36 & 1 & 1 & 0.5 & 5 & 313 \\
\hline 37 & 37 & 1 & 1 & 0.0 & 5 & 323 \\
\hline 38 & 38 & 1 & 1 & 0.1 & 5 & 323 \\
\hline 39 & 39 & 1 & 1 & 0.2 & 5 & 323 \\
\hline 40 & 40 & 1 & 1 & 0.3 & 5 & 323 \\
\hline 41 & 41 & 1 & 1 & 0.4 & 5 & 323 \\
\hline 42 & 42 & 1 & 1 & 0.5 & 5 & 323 \\
\hline 43 & 43 & 1 & 1 & 0.0 & 5 & 333 \\
\hline 44 & 44 & 1 & 1 & 0.1 & 5 & 333 \\
\hline 45 & 45 & 1 & 1 & 0.2 & 5 & 333 \\
\hline
\end{tabular}




\begin{tabular}{|c|c|c|c|c|c|c|}
\hline StdOrder & RunOrder & Blocks & PtType & Concentration & Time & Temperature \\
\hline 46 & 46 & 1 & 1 & 0.3 & 5 & 333 \\
\hline 47 & 47 & 1 & 1 & 0.4 & 5 & 333 \\
\hline 48 & 48 & 1 & 1 & 0.5 & 5 & 333 \\
\hline 49 & 49 & 1 & 1 & 0.0 & 10 & 303 \\
\hline 50 & 50 & 1 & 1 & 0.1 & 10 & 303 \\
\hline 51 & 51 & 1 & 1 & 0.2 & 10 & 303 \\
\hline 52 & 52 & 1 & 1 & 0.3 & 10 & 303 \\
\hline 53 & 53 & 1 & 1 & 0.4 & 10 & 303 \\
\hline 54 & 54 & 1 & 1 & 0.5 & 10 & 303 \\
\hline 55 & 55 & 1 & 1 & 0.0 & 10 & 313 \\
\hline 56 & 56 & 1 & 1 & 0.1 & 10 & 313 \\
\hline 57 & 57 & 1 & 1 & 0.2 & 10 & 313 \\
\hline 58 & 58 & 1 & 1 & 0.3 & 10 & 313 \\
\hline 59 & 59 & 1 & 1 & 0.4 & 10 & 313 \\
\hline 60 & 60 & 1 & 1 & 0.5 & 10 & 313 \\
\hline 61 & 61 & 1 & 1 & 0.0 & 10 & 323 \\
\hline 62 & 62 & 1 & 1 & 0.1 & 10 & 323 \\
\hline 63 & 63 & 1 & 1 & 0.2 & 10 & 323 \\
\hline 64 & 64 & 1 & 1 & 0.3 & 10 & 323 \\
\hline 65 & 65 & 1 & 1 & 0.4 & 10 & 323 \\
\hline 66 & 66 & 1 & 1 & 0.5 & 10 & 323 \\
\hline 67 & 67 & 1 & 1 & 0.0 & 10 & 333 \\
\hline 68 & 68 & 1 & 1 & 0.1 & 10 & 333 \\
\hline 69 & 69 & 1 & 1 & 0.2 & 10 & 333 \\
\hline 70 & 70 & 1 & 1 & 0.3 & 10 & 333 \\
\hline 71 & 71 & 1 & 1 & 0.4 & 10 & 333 \\
\hline 72 & 72 & 1 & 1 & 0.5 & 10 & 333 \\
\hline 73 & 73 & 1 & 1 & 0.0 & 24 & 303 \\
\hline 74 & 74 & 1 & 1 & 0.1 & 24 & 303 \\
\hline 75 & 75 & 1 & 1 & 0.2 & 24 & 303 \\
\hline 76 & 76 & 1 & 1 & 0.3 & 24 & 303 \\
\hline 77 & 77 & 1 & 1 & 0.4 & 24 & 303 \\
\hline
\end{tabular}




\begin{tabular}{|c|c|c|c|c|c|c|}
\hline StdOrder & RunOrder & Blocks & PtType & Concentration & Time & Temperature \\
\hline 78 & 78 & 1 & 1 & 0.5 & 24 & 303 \\
\hline 79 & 79 & 1 & 1 & 0.0 & 24 & 313 \\
\hline 80 & 80 & 1 & 1 & 0.1 & 24 & 313 \\
\hline 81 & 81 & 1 & 1 & 0.2 & 24 & 313 \\
\hline 82 & 82 & 1 & 1 & 0.3 & 24 & 313 \\
\hline 83 & 83 & 1 & 1 & 0.4 & 24 & 313 \\
\hline 84 & 84 & 1 & 1 & 0.5 & 24 & 313 \\
\hline 85 & 85 & 1 & 1 & 0.0 & 24 & 323 \\
\hline 86 & 86 & 1 & 1 & 0.1 & 24 & 323 \\
\hline 87 & 87 & 1 & 1 & 0.2 & 24 & 323 \\
\hline 88 & 88 & 1 & 1 & 0.3 & 24 & 323 \\
\hline 89 & 89 & 1 & 1 & 0.4 & 24 & 323 \\
\hline 90 & 90 & 1 & 1 & 0.5 & 24 & 323 \\
\hline 91 & 91 & 1 & 1 & 0.0 & 24 & 333 \\
\hline 92 & 92 & 1 & 1 & 0.1 & 24 & 333 \\
\hline 93 & 93 & 1 & 1 & 0.2 & 24 & 333 \\
\hline 94 & 94 & 1 & 1 & 0.3 & 24 & 333 \\
\hline 95 & 95 & 1 & 1 & 0.4 & 24 & 333 \\
\hline 96 & 96 & 1 & 1 & 0.5 & 24 & 333 \\
\hline 97 & 97 & 1 & 1 & 0.0 & 48 & 303 \\
\hline 98 & 98 & 1 & 1 & 0.1 & 48 & 303 \\
\hline 99 & 99 & 1 & 1 & 0.2 & 48 & 303 \\
\hline 100 & 100 & 1 & 1 & 0.3 & 48 & 303 \\
\hline 101 & 101 & 1 & 1 & 0.4 & 48 & 303 \\
\hline 102 & 102 & 1 & 1 & 0.5 & 48 & 303 \\
\hline 103 & 103 & 1 & 1 & 0.0 & 48 & 313 \\
\hline 104 & 104 & 1 & 1 & 0.1 & 48 & 313 \\
\hline 105 & 105 & 1 & 1 & 0.2 & 48 & 313 \\
\hline 106 & 106 & 1 & 1 & 0.3 & 48 & 313 \\
\hline 107 & 107 & 1 & 1 & 0.4 & 48 & 313 \\
\hline 108 & 108 & 1 & 1 & 0.5 & 48 & 313 \\
\hline 109 & 109 & 1 & 1 & 0.0 & 48 & 323 \\
\hline
\end{tabular}




\begin{tabular}{ccccccc}
\hline StdOrder & RunOrder & Blocks & PtType & Concentration & Time & Temperature \\
\hline 110 & 110 & 1 & 1 & 0.1 & 48 & 323 \\
111 & 111 & 1 & 1 & 0.2 & 48 & 323 \\
112 & 112 & 1 & 1 & 0.3 & 48 & 323 \\
113 & 113 & 1 & 1 & 0.4 & 48 & 323 \\
114 & 114 & 1 & 1 & 0.5 & 48 & 323 \\
115 & 115 & 1 & 1 & 0.0 & 48 & 333 \\
116 & 116 & 1 & 1 & 0.1 & 48 & 333 \\
117 & 117 & 1 & 1 & 0.2 & 48 & 333 \\
118 & 118 & 1 & 1 & 0.3 & 48 & 333 \\
119 & 119 & 1 & 1 & 0.4 & 48 & 333 \\
120 & 120 & 1 & 1 & 0.5 & 48 & 333 \\
\hline
\end{tabular}

\section{Results and Discussion}

\section{Influence of concentration and temperature}

Figures 2 shows the variation of inhibition efficiency with the inhibitor's concentration and solution's temperature at 5 hours immersion time. The figure clearly shows that the inhibitor's efficiency (inversely the corrosion rates) increases when added the inhibitor to the corrosive environment. This is thought to be due to an increase in the number of molecules that are adsorbed and spread over the mild steel surface.

This adds to the relative corrosion stability and resistance of the surface to corrosion. The inhibitor molecule used contains pairs of electrons on the sulfur, oxygen and nitrogen atoms in addition to resonance effect of the rings and inductive effects benzene ring and this enhances the inhibition efficiency of the inhibitor molecules.

On the other hand, the effect of temperature on the inhibition efficiency is as shown in the figure. Efficiency decreases with temperature. This is not helpful if we look at the corrosive environment under which mechanical parts work in Iraq where summer temperature rises above $50^{\circ} \mathrm{C}$.

Generally, the inhibition efficiency of organic molecules depends on the adsorption/desorption behavior. Inhibiting activity of physisorbed inhibitors decreases with higher temperatures, but for chemisorbed inhibitors, the inhibition efficiency usually increases with higher temperatures $[17,18]$. 


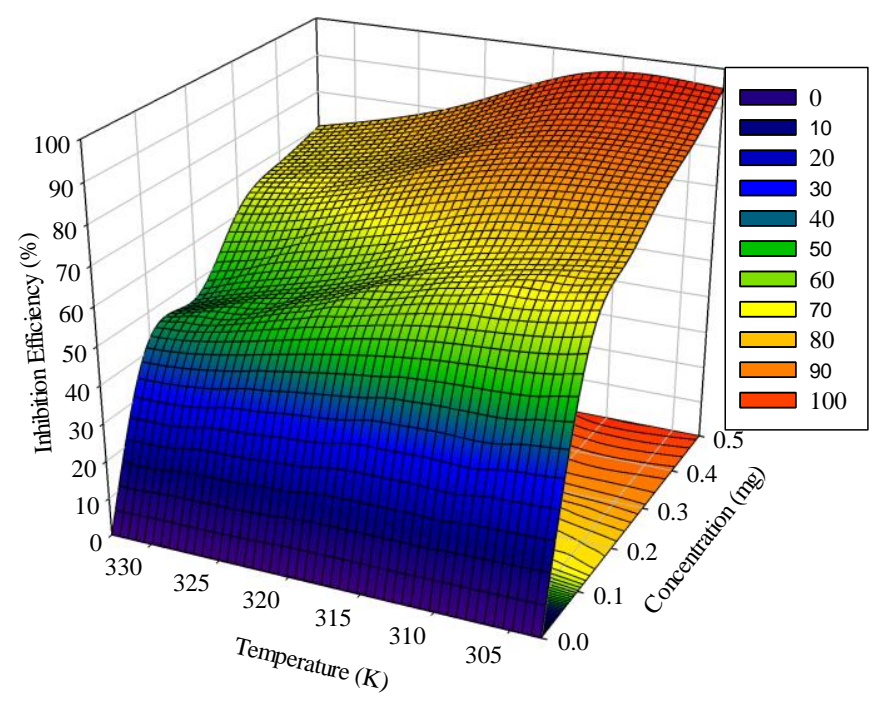

Figure 2. Effect of temperature on inhibition efficiency at different inhibitor concentration and $5 \mathrm{hr}$.

\section{Influence of concentration and time}

The influence of concentration and exposure time of the inhibition efficiency was studied. The obtained results are shown in Figure 3. In general, the corrosion rate (inferred from inhibition efficiency) value was found to decrease with. The higher temperature effect is to speed up the chemical reaction and to reduce oxygen solubility, which allows the occurrence of a cathodic reaction. The Figure also denotes the effect of the inhibitor with a reduction in the mild steel samples' corrosion rate value.

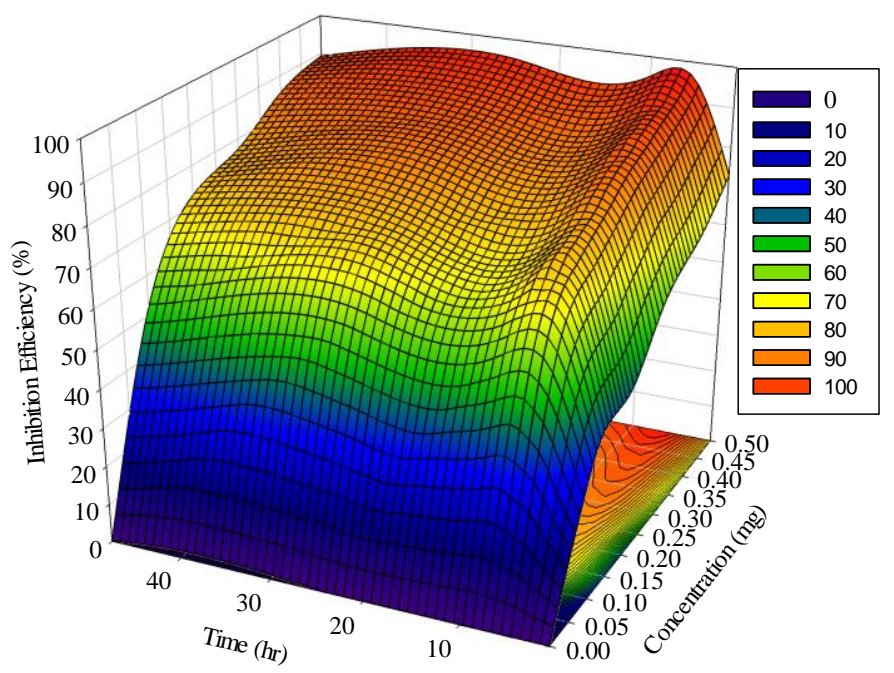

Figure 3. Effect of time on inhibition efficiency at different inhibitor concentrations and $303 \mathrm{~K}$. 
The temperature has a negative effect on the inhibitor efficiency, an increase in temperature results to increase of the dynamic energy for the inhibitor's molecules. The increase in dynamic energy slows the protective film formed on the surface of mild steel samples. With an increase in temperature, the corrosion rate and inhibitors' efficiency decrease.

The corrosion rate value was highest without inhibitor solution, and then it starts to decrease gradually with the presence of inhibitor as shown in Figure 3. However, inhibition efficiency increases with an increase of inhibitor concentration by a linear relationship.

The increase in IC leads to adsorption and surface coverage increase, therefore, leading to a reduction in corrosion rate values. The result indicates that the corrosion rate values decrease with the presence of inhibitor at all concentrations studied.

\section{Influence of temperature and time}

The influence of temperature and exposure time of the inhibition efficiency was studied. The obtained results are shown in Figure 4.

The results of the tests showed that the new corrosion inhibitor was effective in preventing the corrosion of mild steel in the acid environment up to 24 hours and still stable, as shown in Figure 4, but with increasing immersion time more than 24 hours the inhibition efficiency decreased $[10,19,20]$.

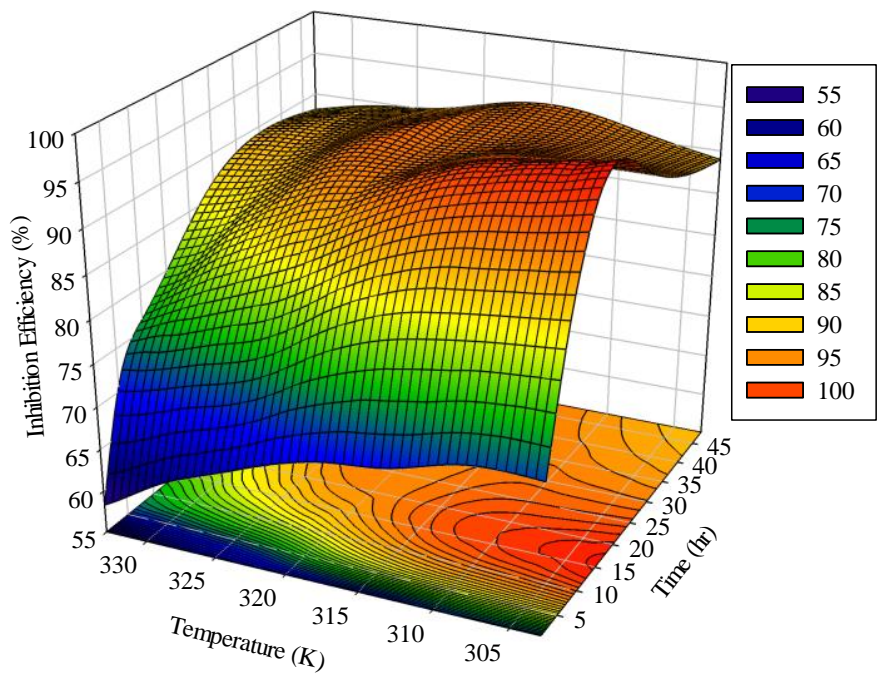

Figure 4. Effect of temperature on inhibition efficiency at different immersion time and $0.5 \mathrm{mg}$.

\section{Development of regression models}

Regression models were obtained for the response data which suggests a quadratic model. This regression model is a modified quadratic model from manual simplification and reduction of the model involving exclusion of high terms that are insignificant to obtain empirical model in terms of actual factors presented in Equation 6 as shown below: 
Efficiency $=-1548+935$ Concentration -8.15 Time +9.80 Temperature 429.2 Concentration $\times$ Concentration -0.03922 Time $\times$ Time 0.01555 Temperature $\times$ Temperature -0.215 Concentration $\times$ Time 1.838 Concentration $\times$ Temperature +0.03417 Time $\times$ Temperature

Both concentration and time are significant to first and second order, time is significant to the first order. Based on the interaction, all terms are significant except that for the interaction between concentration with time. A second-order effect of temperature is insignificant. These results are summarized below in Figure 5.

Table 3 also suggests that there is a strong interaction between the effects of concentration and temperature and insignificant interaction between concentration and time. However, the time and temperature seem to have significant interaction and effect on efficiency.

Table 3. Coded coefficients.

\begin{tabular}{ccccccc}
\hline Term & Coef. & SE Coef. & $\mathbf{9 5 \%}$ CI & T-Value & P-Value & VIF \\
\hline Constant & 97.22 & 2.24 & $(92.78,101.67)$ & 43.34 & 0.000 & \\
Concentration & 32.68 & 1.36 & $(29.98,35.38)$ & 23.99 & 0.000 & 1.16 \\
Time & 17.48 & 1.19 & $(15.12,19.84)$ & 14.68 & 0.000 & 1.00 \\
Temperature & 4.25 & 1.25 & $(1.77,6.72)$ & 3.40 & 0.001 & 1.16 \\
Concentration $\times$ Concentration & -26.83 & 2.16 & $(-31.11,-22.54)$ & -12.41 & 0.000 & 1.00 \\
Time $\times$ Time & -21.66 & 2.26 & $(-26.13,-17.19)$ & -9.60 & 0.000 & 1.00 \\
Temperature $\times$ Temperature & -3.50 & 1.94 & $(-7.35,0.35)$ & -1.80 & 0.074 & 1.00 \\
Concentration $\times$ Time & -1.26 & 1.74 & $(-4.71,2.18)$ & -0.73 & 0.470 & 1.16 \\
Concentration $\times$ Temperature & -6.89 & 1.69 & $(-10.25,-3.53)$ & -4.07 & 0.000 & 1.00 \\
Time $\times$ Temperature & 12.05 & 1.59 & $(8.89,15.20)$ & 7.56 & 0.000 & 1.16 \\
\hline
\end{tabular}

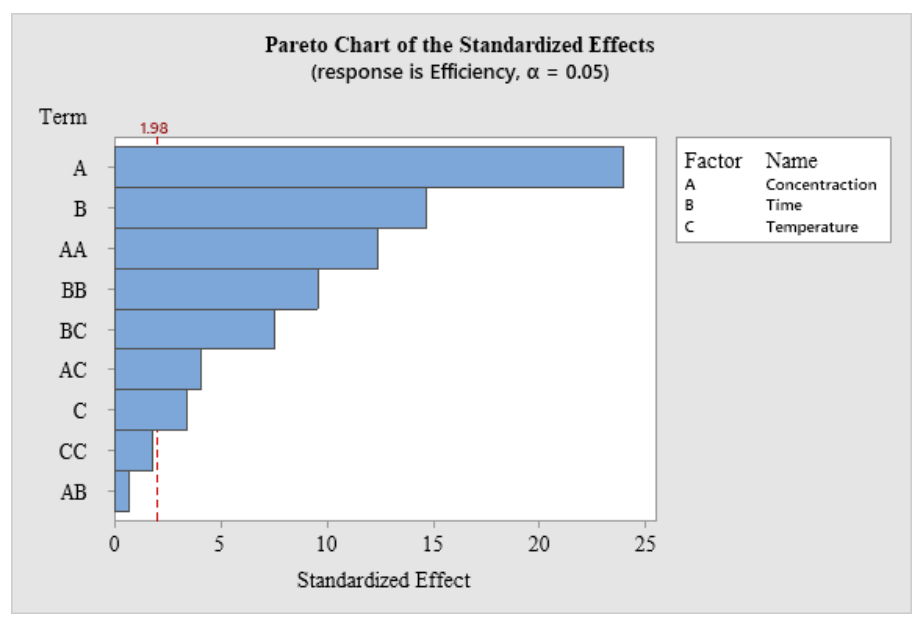

Figure 5. Pareto chart for the main effect. 


\section{Statistical analysis of mild steel corrosion using inhibitor}

The accuracy and significance of the correlation are summarized in the following Table 4 and Figure 6.

Table 4. Model summary.

\begin{tabular}{ccc}
\hline$S$ & R-sq & R-sq(adj) \\
\hline 9.45035 & $96.65 \%$ & $96.96 \%$ \\
\hline
\end{tabular}

The above table shows the accuracy of the model. The obtained result from this study shows that $96.96 \%$ of the inhibitor efficiency total variation relates to experimental variables. The selected factors represent the model obtained and describe the real relationship between the selected factors.

The P-value was used to check the model coefficient significance. The operation parameters were identified to be significant according to the model thereby influencing the responses. Hence, the corrosion of mild steel Type 316 in acidic solution has been proven statistically to depend on the operation parameters according to the frequency of each parameter occurrence in the model (Table 3).

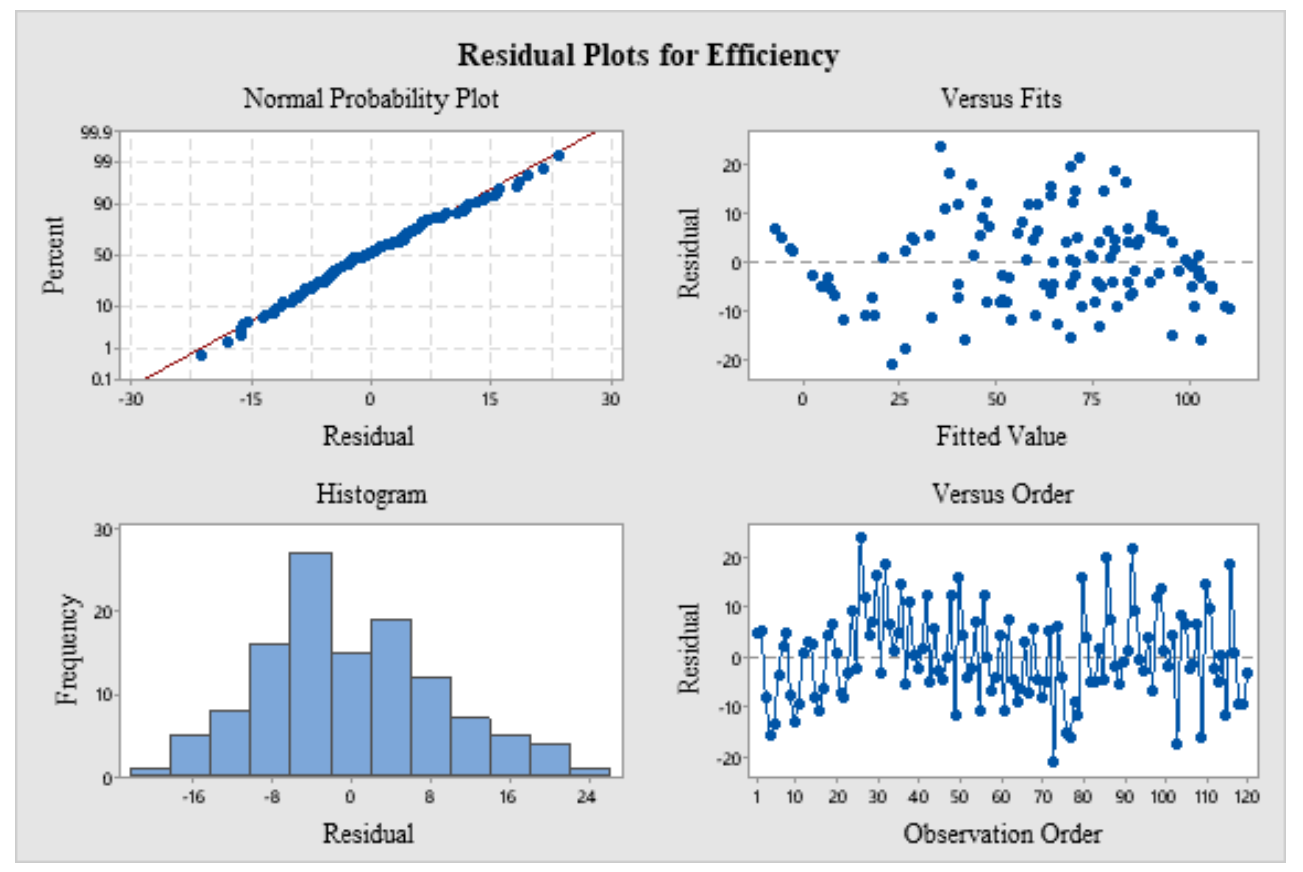

Figure 6. Residual plot for the inhibition efficiency.

\section{Contour plots}

Shown in Figure 7 contour 3-D response surface plot. In the 3-D response plots, the highest response value was ascribed to the factors in the design space as given with the clear peaks. These figures explain the surface behavior of variable combinations on mild steel 
corrosion. The corrosion rate increases when the temperature increases and the inhibitor concentration decreases.

Figure 7-A shows that temperature and inhibitor efficiency were significant on the response, but concentration has a more significant influence than solution temperature. The interaction between both factors was more significant with a negative effect on the response which indicates that an increase in the level of both variables is an inefficient method to reduce $C R$ (also shown in as shown in Figure 2). It also shows that inhibition efficiency increase when the temperature decreases and the inhibitor concentration increase beyond $0.3 \mathrm{~g}$.

At low exposure time, the inhibition efficiency (shown in Figure 7-B) value increased with inhibitor concentration. However, a significant increase in the inhibition efficiency was noticed when inhibitor concentration increased beyond $0.3 \mathrm{~g}$ and time was increased beyond $20 \mathrm{hrs}$.

Figure 7-C suggests that at low concentrations, temperature becomes effective at higher levels of exposure time is increased beyond $25 \mathrm{hrs}$.

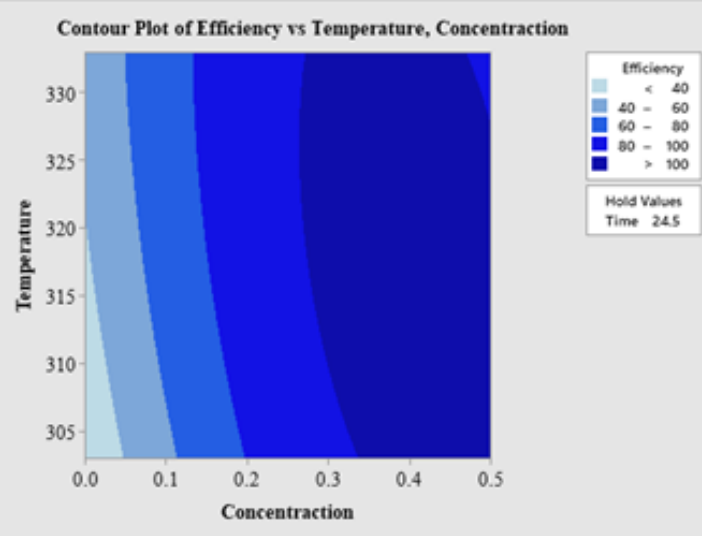

(A)

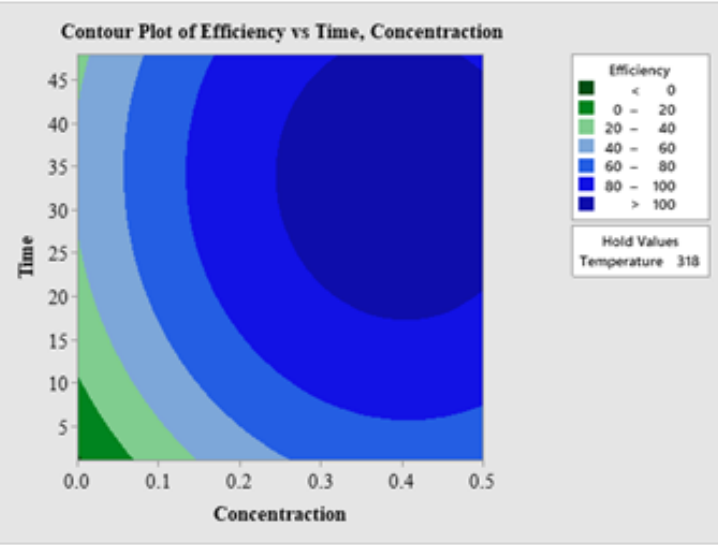

(B)

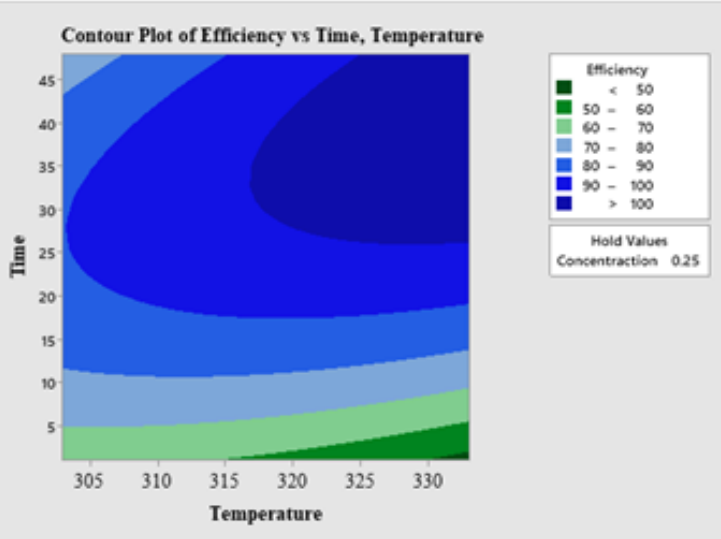

(C)

Figure 7. Contour surface plot for the variables. 


\section{Optimization using desirability approach}

The last main aim of this study was to find the optimum parameters of the process to minimize the corrosion rate from the developed mathematical model equations.

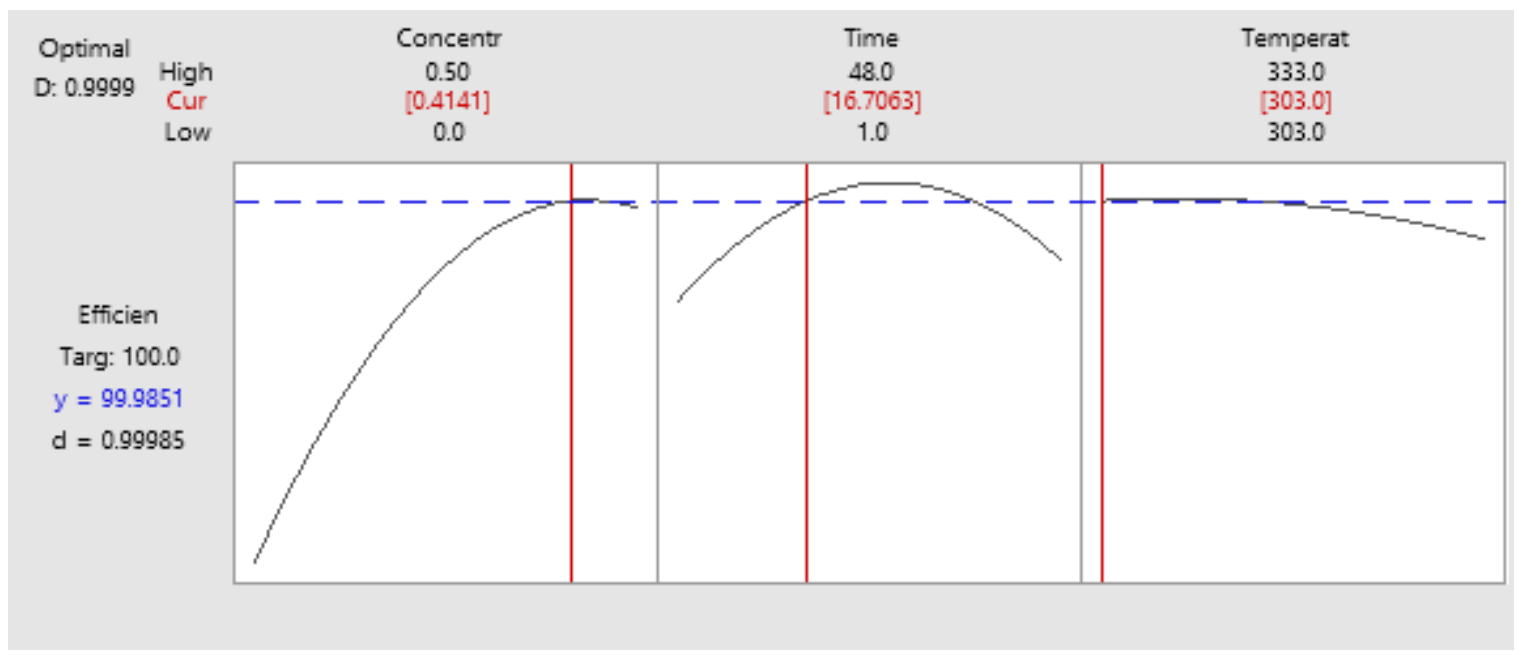

Figure 8. Optimization of variables.

Response surface method via desirability optimization approach was applied. The optimization of the variables was done withing the range studied that gives minimum corrosion rate. The optimum conditions for getting the highest inhibition efficiency (lowest corrosion rate) at static conditions is when the temperature value is equal to $30^{\circ} \mathrm{C}$, exposure time $16 \mathrm{~h}$ and the inhibitor concentration is $0.4 \mathrm{~g} / \mathrm{L}$, as shown in Figure 8.

\section{Conclusion}

Conclusions drawn from the experimental and theoretical results are as follows:

1. An increase in temperature leads to increased corrosion rate and reduced inhibition efficiency.

2. The response surface methodology quadratic model developed showed that temperature and exposure time significantly affects the inhibitor efficiency in sodium chloride solution.

3. The optimum process variable from the quadratic model developed was $0.4141 \mathrm{~g}$ inhibitor concentration, $16.7063 \mathrm{~h}$ exposure time, and temperature of $30^{\circ} \mathrm{C}$ with a predicted optimum inhibitor efficiency value of $100 \%$ using the surface response method for the experiment design.

4. The obtained results from the optimum value validated agree with predicted values by the quadratic model.

\section{Acknowledgments}

This work is based on research supported by the National Research Foundation of South Africa and the Tshwane University of Technology. 


\section{References}

1. C. Alonso, C. Andrade, M. Castellote and P. Castro, Chloride threshold values to depassivate reinforcing bars embedded in a standardized OPC mortar, Cem. Concr. Res., 2000, 30, 1047-1055. doi: 10.1016/S0008-8846(00)00265-9

2. D.S. Zinad, Q.A. Jawad, M.A.M. Hussain, A. Mahal, L. Mohamed and A.A. Al-Amiery, Adsorption, temperature and corrosion inhibition studies of a coumarin derivatives corrosion inhibitor for mild steel in acidic medium: gravimetric and theoretical investigations, Int. J. Corros. Scale Inhib., 2020, 9, no. 1, 134-151. doi: 10.17675/2305-6894-2020-9-1-8

3. Yu.I. Kuznetsov, A.A. Chirkunov and A.M. Semiletov, Progress in the inhibition of metal corrosion and the prospects of its use in the oil and gas industry, Int. J. Corros. Scale Inhib., 2019, 8, no. 4, 850-881. doi: 10.17675/2305-6894-2019-8-4-5

4. A.S. Alshamsi, A.G. AlBlooshi, A.S. Alshamsi, A.Y. Alkaabi, Y.S. Elnasiri and M.M. Aldhaheri, The effects of surface roughness, chloride, and molybdate on the corrosion behavior of iron in bicarbonate/carbonate solutions, Int. J. Corros. Scale Inhib., 2019, 8, no. 4, 835-849. doi: 10.17675/2305-6894-2019-8-4-4

5. I. Ahamad, R. Prasad, and M.A. Quraishi, Thermodynamic, electrochemical and quantum chemical investigation of some Schiff bases as corrosion inhibitors for mild steel in hydrochloric acid solutions, Corros. Sci., 2010, 52, 933-942. doi: 10.1016/j.corsci.2009.11.016

6. S. Junaedi, A. Kadhum, A. Al-Amiery, A. Mohamad and M. Takriff, Synthesis and characterization of novel corrosion inhibitor derived from oleic acid: 2-Amino5Oleyl1,3,4-Thiadiazol (AOT), Int. J. Electrochem Sci., 2012, 7, 3543-3554.

7. I.B. Obot and N.O. Obi-Egbedi, Adsorption properties and inhibition of mild steel corrosion in sulphuric acid solution by ketoconazole: experimental and theoretical investigation, Corros. Sci., 2010, 52, no. 1, 198-204. doi: 10.1016/j.corsci.2009.09.002

8. M.A. Petrunin, N.A. Gladkikh, M.A. Maleeva, L.B. Maksaeva and T.A. Yurasova, The use of organosilanes to inhibit metal corrosion. A review, Int. J. Corros. Scale Inhib., 2019, 8, no. 4, 882-907. doi: 10.17675/2305-6894-2019-8-4-6

9. M. Barrahi, H. Elhartiti, A. El Mostaphi, N. Chahboun, M. Saadouni, R. Salghi, A. Zarrouk and M. Ouhssine, Corrosion inhibition of mild steel by Fennel seeds (Foeniculumvulgare Mill) essential oil in $1 \mathrm{M}$ hydrochloric acid solution, Int. J. Corros. Scale Inhib., 2019, 8, no. 4, 937-953. doi: 10.17675/2305-6894-2019-8-4-9

10. T.A. Salman, A.A. Al-Amiery, L.M. Shaker, A.A.H. Kadhum and M.S. Takriff, A study on the inhibition of mild steel corrosion in hydrochloric acid environment by 4-methyl-2-(pyridin-3-yl)thiazole-5-carbohydrazide, Int. J. Corros. Scale Inhib., 2019, 8, no. 4, 1035-1059. doi: 10.17675/2305-6894-2019-8-4-14

11. J.A. Yamin, E.A.E. Sheet and A.A. Al-Amiery, ANN and DOE Analysis of Corrosion

Resistance Inhibitor for Mild Steel Structures in Iraq, Mod. Appl. Sci., 2019, 13, no. 4, 80-88. doi: $\underline{10.5539 / \mathrm{mas} . v 13 \mathrm{n} 4 \mathrm{p} 80}$ 
12. ASTM G77-98, Standard Test Method for Ranking Resistance of Materials to Sliding Wear Using Block-on-Ring Wear Test, 1998.

13. M. Barrahi, H. Elhartiti, A. El Mostaphi, N. Chahboun, M. Saadouni, R. Salghi, A. Zarrouk and M. Ouhssine, Corrosion inhibition of mild steel by Fennel seeds (Foeniculum vulgare Mill) essential oil in $1 \mathrm{M}$ hydrochloric acid solution, Int. J. Corros. Scale Inhib., 2019, 8, no. 4, 937-953. doi: 10.17675/2305-6894-2019-8-4-9

14. H.R. Obayes, A.A. Al-Amiery, G.H. Alwan, T.A. Abdullah, A.A.H. Kadhum and A.B. Mohamad, Sulphonamides as corrosion inhibitor: Experimental and DFT studies, J. Mol. Struct., 2017, 1138, 27-34. doi: 10.1016/j.molstruc.2017.02.100

15. D. Montgomery, Design and Analysis of Experiments, John Wiley \& Sons, 2017.

16. G.E.P. Box, W.G. Hunter and J.S. Hunter, Statistics for experimenters, an introduction to design, data analysis, and model building, Ed.: B. Heller, John Wiley and Sons, New York, 1978.

17. A. Popova, Temperature effect on mild steel corrosion in acid media in presence of azoles, Corros. Sci., 2007, 49, 2144-2158. doi: 10.1016/j.corsci.2006.10.020

18. F. Bentiss, M. Lebrini and M. Lagrenée, Thermodynamic characterization of metal dissolution and inhibitor adsorption processes in mild steel/2,5-bis( $n$-thienyl)-1,3,4thiadiazoles/hydrochloric acid system, Corros. Sci., 2005, 47, 2915-2931. doi: 10.1016/j.corsci.2005.05.034

19. J. Haque, V. Srivastava, C. Verma, H. Lgaz, R. Salghi and M. Quraishi, N-Methyl$\mathrm{N}, \mathrm{N}, \mathrm{N}$-trioctylammonium chloride as a novel and green corrosion inhibitor for mild steel in an acid chloride medium: electrochemical, DFT and MD studies, New J. Chem., 2007, 41, 13647-13662. doi: 10.1039/C7NJ02254A

20. B. Anwar, T. Khairunnisa and Y. Sunarya, Corrosion inhibition of A516 carbon steel in $0.5 \mathrm{M} \mathrm{HCl}$ solution using Arthrospira platensis extract as green inhibitor, Int. J. Corros. Scale Inhib., 2020, 9, no. 1, 244-256. doi: 10.17675/2305-6894-2020-9-1-15 